\title{
A criança conectada: os youtubers mirins e a promoção de modos de ser criança nas lógicas do consumo
}

\section{Marcelo de Andrade}

Universidade de São Paulo, São Paulo, SP, Brasil

ORCID: http://orcid.org/0000-0002-5300-9258

\section{Gisela G. S. Castro}

Escola Superior de Propaganda e Marketing, São Paulo, SP, Brasil ORCID: http://orcid.org/0000-0003-0662-3770

\section{Resumo}

Este artigo busca refletir sobre os youtubers mirins e os modos de ser criança promovidos por tais personagens. Para isso, tomamos como ponto de análise o canal Crescendo com Luluca, disponível na plataforma do YouTube, para tecer considerações sobre a produção midiática de um tipo de subjetividade que estamos denominando como a criança conectada. Consideramos os youtubers como agentes que promovem certos modos de ser e estilos de vida pautados pelas lógicas do consumo. Nesta nossa análise empírica destacamos três fatores preponderantes nas produções da pequena Luluca: o uso de objetos como marcadores sociais; a tênue fronteira entre a vida privada e pública da youtuber; e o uso de uma linguagem informal e descontraída capaz de gerar proximidade entre a youtuber e seus espectadores-fãs.

\section{Palavras-chave}

Comunicação e consumo. Criança conectada. Modos de ser. YouTube. Youtuber mirim.

\section{Introdução}

Nos últimos anos o número de brasileiros com acesso à internet aumentou de maneira considerável, especialmente quando o acesso é realizado por meio de dispositivos móveis, com destaque para os smartphones. De acordo com os dados da pesquisa TIC Domicílios (CETIC.br, 2018) realizada anualmente pelo Centro Regional de Estudos para o 
Desenvolvimento da Sociedade da Informação ${ }^{1}$ no ano de 2007, o percentual de domicílios com acesso à rede era de apenas 17\%. Dez anos depois, em 2017, esse número saltou para 61\%. Um aumento importante que possibilitou novas formas de interação, comunicação e sociabilidade por meio da internet entre um contingente crescente de pessoas, inclusive crianças.

Apesar do expressivo crescimento, Castro (2012a) nos alerta que é preciso ter uma ideia menos simplista acerca da inclusão digital. Para a autora, não basta apenas ter acesso ao computador e à internet para se servir das possibilidades oriundas das tecnologias digitais online. Concomitantemente com o acesso, faz-se necessário investir na educação para o uso das ferramentas online de modo a propiciar aos usuários conhecimentos mínimos para reconhecer as oportunidades, bem como os riscos espalhados pela rede. Cabe também ponderar que este cenário ainda se faz distante para uma parcela significativa de brasileiros. Portanto, não se pretende neste artigo desconsiderar as desigualdades sociais e econômicas que assolapam de modo evidente o Brasil contemporâneo.

Diante das múltiplas possibilidades provenientes desse contexto conectado, chama atenção a disposição que parte dos usuários apresentam para compartilhar e, até mesmo, elaborar seus próprios conteúdos nas plataformas online. Não por acaso, o que se vê na contemporaneidade é que as produções midiáticas não se restringem aos grandes conglomerados, como as emissoras de TV, rádio, revistas, jornais etc. Em paralelo com tais corporações, muitos dos próprios usuários da rede passaram a produzir conteúdos e distribuí-los nas plataformas de compartilhamento disponíveis no universo digital. Se no modelo das mídias de massa tradicional a informação era majoritariamente transmitida de um polo emissor para muitos receptores, no modelo pós-massivo (LEMOS, 2014), a informação passou a circular de muitos emissores para muitos receptores, instaurando uma estrutura mais participativa, tanto na criação quanto na transmissão de conteúdos no âmbito da comunicação digital em rede.

No caso deste artigo, deter-nos-emos a refletir sobre as produções publicadas em um site específico, o YouTube ${ }^{2}$, plataforma de compartilhamento de vídeos que, de certa

\footnotetext{
1 O Cetic.br tem por objetivo monitorar a adoção das tecnologias de informação e comunicação (TIC), em particular, o acesso e uso de computador, internet e dispositivos móveis. Foi criado em 2005 e é um departamento do Núcleo de Informação e Coordenação do Ponto BR (Nic.br), uma entidade civil, sem fins lucrativos, que implementa decisões e projetos do Comitê Gestor da Internet no Brasil.

2 YouTube é uma plataforma de compartilhamento de vídeos. Na atualidade aparece como a principal plataforma para esta finalidade na internet. Para mais informações acessar: https://www.youtube.com . Acesso em maio/2020.
} 
maneira, abriu espaço para que novos produtores, inclusive certas crianças, ganhassem visibilidade e passassem a ocupar uma posição de destaque na cena midiática vigente.

A apropriação do YouTube como um espaço no qual pessoas anônimas vislumbram a possibilidade de produzir e compartilhar seus próprios conteúdos fez emergir uma categoria específica utilizada para denominar esses produtores: são os chamados youtubers. Entende-se por youtuber o internauta que cria e publica seu vídeo na rede utilizando como suporte o site do YouTube. Quando o youtuber é uma criança ${ }^{3}$, dá-se o nome de youtuber mirim. Esta é uma categoria peculiar de produtores de conteúdo que vem ganhando destaque e atenção, bem como despertando certa dose de inquietação. Segundo os dados de pesquisa realizada pelo ESPM Media Lab, a categoria youtuber mirim apresentou em 2016 um crescimento de 564\% em relação ao ano anterior (CORRÊA, 2016). Um sinal de que há disponibilidade e interesse também por parte das crianças em participar e interagir nos sites de redes sociais desempenhando não apenas o papel de espectadores, mas assumindo o protagonismo também como produtores.

Diante desse panorama, este artigo tem como objetivo refletir sobre os youtubers mirins não somente como produtores de conteúdo, mas como figuras midiáticas que promovem certos modos de ser criança, jeitos de brincar e de estar juntos em um mundo crescentemente regido pelas lógicas de consumo e conectado por redes de informação e comunicação. Para embasar nossa reflexão, valemo-nos de aportes teóricos de Aidar Prado (2013), Buckingham (2007), Carrascoza (2014), Castro (2008, 2012, 2013, 2018), Costa (2003), Corrêa (2015, 2015a, 2016), Davis (2013), Douglas e Isherwood (2013), Perez e Trindade (2017), Tomaz (2019), Rocha (2010) e Wernick (2003). Trata-se de mobilizar fundamentos teórico-conceituais que nos ajudem a elucidar os youtubers mirins como um fenômeno midiático e, sobretudo, como atores sociais que contribuem para a constituição de determinados modos de ser criança, os quais são fortemente marcados pela articulação entre comunicação e consumo, entendidos aqui como vetores emblemáticos do contemporâneo.

\section{Youtuber mirim: estrela infantil e inquietante produto midiático}

o YouTube é na atualidade uma das principais plataformas utilizadas para o

3 De acordo com o artigo 2o do ECA (Estatuto da Criança e do Adolescente) considera-se criança a pessoa até doze anos de idade incompletos, e adolescente aquela entre doze e dezoito anos de idade. Disponível em: http://www.planalto.gov.br/ccivil_03/leis/L8069Compilado.htm. Acesso em maio/2020. 
compartilhamento de vídeos na internet. Fundado por Chad Hurley, Steve Chen e Jawed Karin, o site foi lançado no ano de 2005. No ano seguinte, em 2006, foi adquirido pelo Google por cerca de US\$1,65 bilhão (LEITE, 2006). Atualmente a plataforma de vídeos é o segundo site mais acessado em todo o mundo, ficando atrás apenas do principal site da companhia, o site de busca do Google (ALEXA, 2020).

Para Jean Burgess e Joshua Green (2009), a plataforma apresenta uma relação cada vez mais complexa entre consumidores e produtores no que diz respeito à criação de significado e valor. Ao participarem ativamente da produção dos conteúdos que circulam pelo site, os consumidores estão também contribuindo para a formação de novos valores culturais, sociais e econômicos. Corroborando com tal perspectiva, Luciana Corrêa (2015, p. 2) ressalta que o YouTube, de certo modo, "[...] abriu espaço e oportunidade para novos produtores antes desconhecidos ganharem visibilidade.". Para efeitos da nossa presente discussão, destacamos que por meio do YouTube tornou-se possível, inclusive para certas crianças, deixar o anonimato e figurar em uma posição de destaque mesmo em um ambiente que, a princípio, não seria indicado a elas, mas teria sido apropriado por elas.

Embora o Google apresente em suas políticas de uso a informação de que no Brasil a idade mínima para criar uma conta na plataforma é de 18 anos, o que se vê atualmente é uma crescente expansão de canais direcionados às crianças. Em estudo realizado pelo ESPM Media Lab sobre o consumo de vídeos por crianças entre 0 e 12 anos no YouTube, Corrêa (2015a) identificou que entre os 100 canais de maior audiência na plataforma, 36 deles eram voltados a crianças, chegando a 17 bilhões de visualizações em 2015. No ano seguinte, ao atualizar a pesquisa, Corrêa (2016) identificou que entre os 100 canais de maior audiência, o número de canais direcionados ao público infantil tinha saltado para 48, somando um montante de 50 bilhões de visualizações em 2016. Mesmo o YouTube sendo, a priori, um ambiente que não teria sido pensado para as crianças, percebe-se que a plataforma se tornou em um ambiente midiático apropriado por elas. Assim, é em meio à eclosão de novos atores sociais formados por um conjunto crescente de crianças que a categoria dos youtubers mirins ganha destaque. Produtores infantis que levam para o âmbito público questões que, até então, se restringiam ao âmbito privado e colocam em circulação temáticas pertencentes ao universo infantil.

De acordo com Renata Tomaz (2019), as primeiras notícias apresentadas pela grande imprensa brasileira acerca dos youtubers mirins surgiram no ano de 2015, impulsionadas pelo aumento progressivo de crianças que reuniam milhares de inscritos em 
seus canais online. Tomaz (2019) argumenta que é possível considerar a presença de tais personagens, ao menos, sob duas perspectivas:

\begin{abstract}
Uma diz respeito ao reconhecimento da voz das crianças, vinculado a uma configuração de elementos históricos e socioculturais, que possibilitam conceber a participação das crianças na vida social. A outra condição está relacionada a um espaço disponível para que elas possam manifestar essa presença, em particular a mídia. (TOMAZ, 2019, p. 60).
\end{abstract}

Desse modo, podemos considerar que os sites de redes sociais se estabelecem como espaços nos quais as crianças podem manifestar sua presença e ganhar visibilidade no cenário midiático vigente.

Por essa ótica, além da plataforma operar como um espaço disponível para as crianças manifestarem sua presença, o YouTube também se caracteriza por exaltar aspectos relacionados à informalidade da vida cotidiana, forjando um ambiente no qual se torna permitido realçar tudo aquilo que não é visto em outros meios, como a TV e a imprensa, por exemplo. Para Perez e Trindade (2017), os youtubers fazem uso sistemático de uma linguagem que brinca com o espontâneo e com o erro, característica que contribui para gerar identificação do público com essas figuras midiáticas infantis e, até mesmo, com os seus modos de ser e os estilos de vida.

Estrelas resplandecentes na visibilidade midiática que se tornou um valor central do contemporâneo, os youtubers mirins se transformaram, eles próprios, em um atraente e igualmente inquietante produto. Além de consumir os vídeos que são compartilhados pelos youtubers, seus espectadores consomem, sobretudo, essas personalidades infantis como exemplos de modos adequados e, até mesmo, desejáveis e bem-sucedidos de ser criança no mundo atual.

\title{
30 apelo publicitário e a criança conectada
}

Segundo David Buckingham (2007), nos últimos cinquenta anos houve um aumento considerável na escala das atividades de consumo. Concomitantemente com o aumento no consumo, houve também uma expansão no número de produtos ofertados pelo mercado. Neste enredo de crescimento, tanto no consumo quanto na oferta de bens, as crianças também despontam para o mercado como um público de grande interesse, algo muito similar com o observado com os adolescentes no pós-guerra. 
Assim como os adolescentes foram aparentemente "descobertos" como um grupo consumidor diferente durante a expansão econômica no pós-guerra, agora as crianças é que se tornaram um dos alvos mais procurados pelo marketing segmentado (BUCKINGHAM, 2007, p. 211-212).

No entanto, no momento vigente, o consumidor não é segmentado apenas levando em consideração, por exemplo, sua classificação etária, a qual contribui para instituir grandes segmentos de mercado como os das crianças, dos adolescentes, adultos e idosos. Para além de questões amplas de segmentação, agora os consumidores são categorizados de modo mais refinado, considerando especialmente suas práticas e estilos de consumo. Para Castro (2008), esse fenômeno pode ser denominado como hipersegmentação. De modo crescente, a classificação dos consumidores vem sendo pautada por diversos aspectos, desde faixas etárias, gêneros, tipo de esporte preferido, grupo socioeconômico ao qual pertence, até as práticas de consumo que perfazem estilos de vida, formando segmentos cada vez mais sofisticados. Cada perfil assim finamente categorizado corresponde a segmentos ou nichos cujo potencial o mercado procura explorar.

Em decorrência da hipersegmentação, empresas passam a empregar esforços em diferentes estratégias mercadológicas a fim de organizar um ambiente no qual a interação entre as marcas e seu público aconteça, incluindo aqui a ênfase em cativar a atenção do público infantil. Neste caso, busca-se estabelecer novas práticas comunicacionais que viabilizem a interação empresa/criança, produto/consumidor. Se considerarmos que no Brasil há regulamentações que normalizam a publicidade, sobretudo quando direcionada ao público infantil, a comunicação mercadológica voltada para crianças no ambiente online se torna uma questão, no mínimo, problemática.

Por décadas, as empresas encontraram nos intervalos comerciais dos programas infantis veiculados na TV aberta a principal forma para conquistar a atenção da criança. Porém, nas últimas décadas, foi perceptível o desaparecimento dos espaços destinados à criança na grade das principais emissoras no Brasil. De fato, não se pode atribuir uma razão única para tal sumiço, mas há alguns pontos que nos levam a delinear certas hipóteses.

Uma das razões que certamente contribuiu para a derrocada da programação infantil nos canais abertos pode estar intimamente relacionada com a publicação, em março de 2014, da Resolução 163 do Conselho Nacional dos Direitos da Criança e do Adolescente (CONANDA, 2014), a qual dispõe sobre a abusividade do direcionamento da comunicação mercadológica à criança e ao adolescente nos meios de comunicação. 
Partindo do pressuposto de que a publicidade é sabidamente um dos pilares que sustentam a TV aberta no Brasil e, consequentemente, gera recursos para a exibição de programas dirigidos aos segmentos dos produtos anunciados, fica especialmente marcante, neste caso, o fato de que se não há publicidade dirigida à criança, também não há programação para o público infantil neste ambiente.

Diante da debandada da publicidade dirigida à criança em ambientes midiáticos cuja importância era notável, diferentes empresas de produtos infantis se esforçam para estabelecer novas abordagens para chegar até esse público. Neste sentido, as tecnologias digitais, sobretudo os sites de redes sociais, revelam-se ambientes possíveis para reestabelecer o vínculo direto entre empresa e público, especialmente considerando que o universo digital ainda carece de regulamentação. Desse modo, corporações lançam mão não apenas de novos formatos midiáticos para interpelar as crianças, como também de outros formatos de narrativas publicitárias.

Na empreitada mercadológica vigente, muito mais do que simplesmente exaltar os produtos, a publicidade contemporânea busca exaltar o simbólico e o afetivo. A ênfase que no capitalismo industrial era direcionada para a produção material, no capitalismo pósindustrial passa a ser canalizada para a imaterialidade dos aspectos intangíveis das marcas e bens de consumo, uma vez que na publicidade contemporânea, para além de consumir produtos e serviços, "[...] consomem-se estilos de vida, formas de sociabilidade e modos de ser." (CASTRO, 2013, p. 1). Assim, as marcas não apenas enfatizam os atributos dos produtos anunciados, como também enaltecem os aspectos relacionados à emoção e intangibilidade. Para Carrascoza (2014, p. 57), “[...] com a comoditização dos produtos, o apelo publicitário às emoções, aos benefícios sensoriais capazes de levar o público à identificação com um determinado estilo de vida, tornou-se prevalente".

A constituição desse laço afetivo característico da publicidade contemporânea pode ser percebida de modo recorrente nas produções dos youtubers mirins. Valendo-se de uma linguagem amigável e afetuosa, tais personagens procuram a todo tempo gerar certo grau de empatia e proximidade com seus espectadores. Potencializa-se a convocação dos seus milhares de amigos a permanecerem conectados, consumindo e compartilhando os variados vídeos publicados nos canais. Neste caso, a convocação "[...] diz respeito às instigantes e sedutoras formas de interpelação da comunicação mercadológica, que visam manter pelo maior período de tempo possível o consumidor conectado às mídias digitais [...]" (CASTRO, 2018, p. 79-80). Não por acaso, tornou-se fundamental para a comunicação contemporânea 
constituir um ambiente afetivo no qual o consumidor permaneça conectado e consumindo os produtos que são promovidos, bem como os modos de ser e os estilos de vida adequados a tais bens de consumo. E, para isso, o entretenimento se revela um importante artifício.

É por meio das lógicas do entretenimento que as empresas buscam cativar a atenção e o interesse do espectador, forjando um ambiente no qual o objetivo é aumentar o tempo que o consumidor permanece em contato com a marca. Em um cenário com regulamentações que impactam a publicidade dirigida ao público infantil, em especial nos meios tradicionais, a criança que brinca em frente a uma câmera e agrega legiões de seguidores mirins em seu canal online se torna, ela própria, um relevante produto para o mercado: a garota-propaganda que conversa diretamente com seus espectadores mirins.

Defendemos, portanto, que as crianças, principalmente representadas neste artigo pelas figuras das youtubers mirins, estariam consolidando um certo modo de subjetivação ao demonstrarem a seus milhares de espectadores como brincar, do que brincar, com quem brincar e, sobretudo, como ser criança em meio a essa conjuntura conectada. Constitui-se, assim, a criança conectada como um tipo de subjetividade que é consistentemente apresentado como um modo atual, divertido e desejável de ser criança.

Destacamos a criança conectada como um sujeito que brinca diante da câmera e contribui para produzir os modos de brincar e ser criança em um cotidiano permeado pelas plataformas online. Portanto, quando usamos esta expressão, não estamos apenas enfatizando o fato de que as crianças estão progressivamente mais conectadas aos dispositivos digitais. Defendemos que para além de consumir, curtir e compartilhar diferentes conteúdos pela rede, a criança conectada também contribui para demarcar e difundir certos estilos de vida, modos de brincar e ser criança em linha com o protagonismo dos dispositivos conectados à internet na contemporaneidade. Pela nossa perspectiva, os youtubers mirins, figuras altamente conhecidas na plataforma do YouTube, contribuem com um processo de subjetivação que indica os modos considerados adequados e bem-sucedidos de ser criança no mundo atual. Um tipo de subjetividade em que a presença de bens de consumo é invariavelmente marcante e, de certo modo, inquietante, tendo em vista que ao mesmo tempo distingue e eleva simbolicamente aqueles que possuem determinados bens e, por outro lado, segrega aqueles que não têm acesso a tais objetos de desejo e, por consequência, a tais estilos de vida. 


\section{0 modo de ser youtuber: analisando o canal Crescendo com Luluca}

Como pudemos observar, as crianças estão progressivamente ganhando destaque no YouTube, tanto na produção quanto no consumo dos vídeos na plataforma. No entanto, é preciso reconhecer que o consumo das produções compartilhadas pelos youtubers mirins não se limita apenas aos conteúdos dos vídeos. Neste tópico, nosso intuito é destacar algumas questões que contribuem para melhor interpretar a emergência dos youtubers mirins e, principalmente, problematizar os modos de ser e estilos de vida salientados por essas pequenas celebridades infantis.

Para tal análise, utilizamos como objeto empírico os vídeos publicados ao longo do mês de dezembro de 2017 no canal Crescendo com Luluca, disponíveis na plataforma do YouTube. A escolha do canal analisado ocorreu levando em consideração dois fatores: o primeiro diz respeito ao próprio nome do canal, por nos dar indícios de que o crescimento da youtuber é publicizado midiaticamente e pode ser acompanhado em suas diferentes facetas. A segunda razão para escolha se deu por um aspecto puramente quantitativo, uma vez que consideramos o número de pessoas inscritas no canal que, neste caso, deveria ultrapassar a marca de dois milhões de seguidores.

Apresentado por Luíza, uma menina de 9 anos de idade moradora da cidade de São Paulo, o canal conta atualmente 4 com cerca de cinco milhões de inscritos. Com mais de um vídeo novo toda semana, Luluca aborda diversos temas, sempre ligados ao cotidiano infantil. Exibe brinquedos, coleções, como também as brincadeiras que realiza com familiares e amigos, realçando diferentes peculiaridades do seu dia a dia.

Figura 1 - Youtuber mirim protagonista do canal Crescendo com Luluca

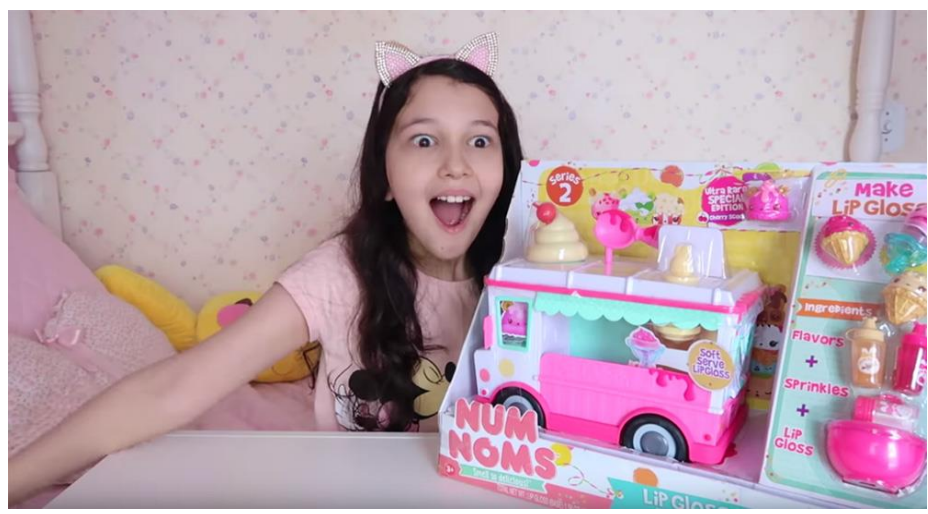

Fonte: CANAL YOUTUBE Crescendo com Luluca, 2020

4 Dados atualizados em julho de 2019 
A ausência da fronteira que separa a vida privada e pública de Luluca é um quesito bastante significativo nas produções da youtuber. Basta ver que as particularidades da rotina cotidiana da menina interagem como parte integrante do espetáculo midiático no qual a presença de objetos é sistematicamente destacada. Não por acaso, Luíza demonstra majoritariamente em seus vídeos uma relação especial com brinquedos e objetos que operam simbolicamente como marcadores sociais em um contexto que, como dissemos, é fortemente alicerçado pelas lógicas de consumo.

Ao refletir sobre os objetos como elementos de marcação e diferenciação social, Jurandir Costa (2003, p. 80) argumenta que “[...] objetos de consumo agregam valor social aos portadores.". Atuam como uma espécie de crachá que possibilita a identificação daquele que é bem colocado ou se apresenta como um vencedor em qualquer lugar ou situação. Corroborando com tal argumento, Douglas e Isherwood (2013) defendem que os bens atuam como mediadores da experiência social, pois transmitem valores e, assim tornam evidentes as hierarquias.

A ênfase nos objetos como marcadores sociais é especialmente pertinente na análise da youtuber mirim, cujas produções ficaram amplamente conhecidas justamente pela presença constante de objetos de consumo que reforçam o status social da menina Luluca. De fato, os objetos demonstrados nos vídeos estão disponíveis a todos, porém é importante destacar que não estão ao alcance de todos, e, portanto, distinguem os que possuem daqueles que apenas contemplam. Essa distinção acontece, em grande medida, porque comprar é um ato econômico com implicações sociais. "Diante de atos desse tipo somos todos diferentes e desiguais." (COSTA, 2003, p. 77).

No entanto, a hierarquização social que os bens de consumo promovem não está relacionada apenas ao poder econômico, mas a uma espécie de acordo coletivo. Segundo Douglas e Isherwood (2013), a importância de um determinado bem de consumo não é dada simplesmente pelo próprio objeto, mas os significados são atribuídos em meio a relações sociais e culturais. 0 objeto material não abarca por si só um sentido. Este significado é conferido em concordância com o outro, sendo construído nas relações entre todos os bens. No caso de Luluca, a diferenciação social exercida por meio dos bens de consumo só é possível porque cada pessoa, neste caso espectador, julga aquele objeto como algo que merece ou não importância. Assim, “[...] cada indivíduo está no esquema de classificação cujas discriminações está ajudando a estabelecer." (DOUGLAS; ISHERWOOD, 2013, p. 121). 
Everardo Rocha (2010) nos lembra que os objetos não são consumidos de forma neutra, mas carregam um universo de distinções.

Com base nos aportes teóricos até aqui mobilizados, defendemos que ao promover certos bens de consumo, a youtuber está também demarcando sua posição social e promovendo a si mesma, seu estilo de vida e seu modo de ser criança como modelo. A menina que aparentemente brinca de modo espontâneo em frente à câmera é a mesma que promove o consumo de determinados brinquedos e modos de brincar que, nesta conjuntura, são apregoados como elementos certos para gozar da boa vida tal qual a demonstrada pela youtuber.

Ao tratar sobre as convocações dos dispositivos comunicacionais para o consumo, José Luiz Aidar Prado (2013) faz uma reflexão bastante pertinente acerca de como os meios de comunicação interpelam os espectadores a seguirem modos de ser que são alardeados como o modo correto para se chegar a uma vida de sucesso, felicidade e bem-estar. $\mathrm{O}$ autor enfatiza que as convocações "[...] chamam os espectadores e leitores para ensinar como viver, como ter sucesso [...]" (2013, p. 169). No caso da discussão proposta por este artigo, as convocações ensinariam também como ser criança no mundo conectado em que vivemos.

Por essa mesma perspectiva, Gisela Castro (2018) identifica a produção de determinados tipos de subjetividades segundo os imperativos daquilo que ela denomina como o coaching midiático vigente. Para Castro (2018, p. 85), o coaching midiático pode ser entendido como "[...] a promoção de modos de ser e estilos de vida baseados em práticas de consumo na pedagogia social desenvolvida pelos mais diversos dispositivos midiáticos". Neste caso, há uma modulação das subjetividades por meio das lógicas do consumo que evidenciam os modos de ser que são considerados adequados e desejáveis: o jeito certo de ser e de viver nos dias de hoje. Por outro lado, essas mesmas lógicas do consumo segregam aqueles que não têm acesso ao conjunto de bens que sustentam esses modos de ser e, portanto, não adotam tais estilos de vida eleitos como os representantes da boa vida.

Parece-nos bastante pertinente acrescentar a estas reflexões o argumento de Andrew Wernick (2003) sobre a prevalência no contemporâneo do que ele denomina como a cultura promocional. $\mathrm{O}$ autor britânico defende a tese de que a linguagem publicitária, que antes se restringia apenas ao âmbito relacionado ao mundo da publicidade, teria se espraiado para quase todas as instâncias da vida em sociedade. Essa disseminação, segundo ele inédita, definiria a nossa cultura como eminentemente promocional. Na visão do autor, na cultura promocional produz-se continuamente um eu para a circulação competitiva, uma 
projeção adequada que inclui não apenas as roupas, os discursos, os gestos e a ação, como também toda a constituição de modos de ser considerados admiráveis e bem-sucedidos. Davis (2013), partilha da mesma tese e enfatiza que a cultura promocional - entendida aqui como uma ênfase contínua e perniciosa na autopromoção - tem se tornado a parte central e mais influente da comunicação e das relações sociais. Desse modo, na contemporaneidade promove-se praticamente tudo, tanto produtos, marcas e objetos de consumo, como também pessoas, visões de mundo e estilos de vida.

Diante desse conjunto de argumentos, é possível compreender que no canal analisado, a própria figura de Luluca torna-se o produto midiático a ser consumido. Ao promover a si mesma, seus modos de ser e estilos de vida como sendo os modos admiráveis de ser criança, contribui para um processo de subjetivação baseado nas lógicas de consumo. Ao se identificarem com os estilos de vida demonstrados por Luíza, muitos dos seus seguidores vislumbram na própria figura da youtuber, o modo correto e desejável de ser uma criança de sucesso no momento vigente. Esse aspecto de identificação contribui para que grande parte do seu público passe a desejar levar a vida seguindo os estilos e modos de ser preconizados por Luíza. Amplia-se, assim, a quantidade de fãs que seu canal abarca e, consequentemente, o valor de Luluca como produto no competitivo mercado das garotaspropaganda online.

Em artigo publicado em 2012, Castro faz uma reflexão sobre a constituição do consumidor-fã nas redes sociais online. A autora entende por consumidor-fã aquele indivíduo que além de consumir os produtos, também compartilha conteúdos, participa de discussões e rege sua vida pautada pelo estilo de vida proposto pela marca em questão. Em um cenário com grande necessidade de direcionar esforços para a sedução do consumidor, visto a atual saturação da mensagem publicitária, o fator de identificação passa a ser perseguido pelas empresas no intuito de transformar clientes em fãs, o consumidor em um colaborador e principal divulgador da marca (CASTRO, 2012).

Mobilizando tais fundamentos para pensar os youtubers mirins, percebe-se que nas produções de Luluca isso não é diferente. Nos vídeos analisados busca-se a todo momento gerar o reconhecimento entre o produtor (Luluca) e o consumidor (o espectador). De maneira calculada para parecer divertida e informal, Luíza procura se mostrar uma criança comum como qualquer outra da sua idade. Para isso, vale-se de um artifício reiteradamente presente nas produções dos youtubers: o erro, que ao invés de ser editado e deixado de fora da produção final ganha um papel de destaque no intuito de conferir autenticidade ao 
conteúdo veiculado como uma produção infantil e espontânea.

Nos vídeos da youtuber há sempre uma ocasião na qual o erro é explicitado, sendo praticamente impossível passar despercebido. A imagem modifica suas tonalidades e, no momento em que o erro é marcado, o vídeo perde suas cores e passa a ser exibido em tons de preto e branco, simulando uma espécie de making of ou cenas de bastidores. Um recurso que possibilita destacar Luíza como uma garota comum que, evidentemente, também erra. Neste caso, o erro parece ser um artifício cuidadosamente pensado como uma forma de potencializar a identificação e o vínculo afetivo entre a youtuber e seus consumidores-fãs. Para Perez e Trindade (2017, p. 15), esse componente de amadorismo e informalidade presente nas produções dessas figuras “[...] sugere que estes indivíduos são semelhantes ao seu público. Esta aura amadora traz espontaneidade, descontração, empatia que possibilita o vínculo identitário com o público - 'o youtuber é como eu' ".

Consideradas as mais novas celebridades no cenário midiático vigente, os youtubers mirins estão também contribuindo para produzir determinados modos de subjetivação. A criança que brinca diante da câmera também demonstra certos estilos de vida e modos de brincar. Nesse contexto, a presença de bens de consumo e a destreza no manuseio de plataformas midiáticas online se apresentam como elementos indispensáveis e até mesmo necessários ao ser criança hoje.

\section{Considerações finais}

Como não poderia deixar de ser, os youtubers mirins formam um complexo fenômeno midiático que vem atraindo a atenção de anunciantes interessados em dirigir seus esforços junto ao público infantil. Devido a regulamentações impostas à veiculação da publicidade destinada à criança e ao adolescente no Brasil, os canais dos youtubers mirins se revelam um campo fértil para a propagação de marcas e produtos.

Pautados pelas lógicas do entretenimento, essas figuras infantis compartilham com seus milhares de seguidores uma variedade de informações de toda natureza, inclusive detalhando produtos, bem como demonstrando certos estilos de vida que são continuamente atrelados a determinadas marcas e mercadorias.

Ao longo deste artigo, buscamos problematizar a aparente espontaneidade dos youtubers mirins diante da câmera. Para além das supostas brincadeiras ali encenadas, essas pequenas personalidades atuam na promoção e na propagação de determinados modos de 
ser criança, os quais são ancorados nas dinâmicas do entretenimento e nas lógicas do consumo.

A construção da figura de Luluca está, assim, invariavelmente vinculada a diferentes marcas e objetos que contribuem de modo paradoxal para promover a identificação, como também a distinção entre a youtuber e seu público. Ao mesmo tempo em que Luíza se apresenta como uma garota qualquer, ela também exibe em seu cotidiano midiático uma notável desenvoltura no manejo de linguagem, plataforma, brinquedos e produtos considerados admiráveis e desejáveis por parte de sua gigantesca base de fãs, tornando-se, ela própria, um produto midiático altamente lucrativo e desejável como modelo de personagem bem-sucedido no mundo atual.

Muito além das brincadeiras com as quais divertem o seu público, é preciso reconhecer que as pequenas youtubers estão demonstrando e, ao mesmo tempo, ajudando a promover certos modos de brincar e ser criança em um contexto em que comunicação e consumo se apresentam como esteios do bem-viver.

\section{Referências}

AIDAR PRADO, José Luiz. Convocações biopolíticas dos dispositivos comunicacionais. São Paulo: EDUC: FAPESP, 2013.

ALEXA. The top 500 sites on the web. 2020. Disponível em: https://www.alexa.com/topsites. Acesso em: maio 2020.

BUCKINGHAM, David. Crescer na era das mídias eletrônicas. São Paulo: Loyola, 2007.

BURGESS, Jean; GREEN, Joshua. YouTube e a revolução digital: como o maior fenômeno da cultura participativa transformou a mídia e a sociedade. São Paulo: Aleph, 2009.

CANAL YOUTUBE. Crescendo com Luluca. YouTube, 2020. Disponível em: https://www.youtube.com/channel/UCnrGkE2AmBAv6Vxj6kjf1jg. Acesso em: maio 2020.

CARRASCOZA, João Anzanello. Estratégias criativas da publicidade: consumo e narrativa publicitária. São Paulo: Estação das Letras e Cores, 2014.

CASTRO, Gisela G. S. Mídia, consumo, globalização e contemporaneidade. In. BACCEGA, Maria Aparecida. (org.). Comunicação e culturas do consumo. São Paulo: Atlas, 2008, p. 132-144.

CASTRO, Gisela G. S. Entretenimento, sociabilidade e consumo nas redes sociais: cativando o consumidor fã. Fronteiras: estudos midiáticos, São Leopoldo, v. 14, n. 2, p. 133-140, 2012. 
CASTRO, Gisela G. S. Screenagers: entretenimento, comunicação e consumo na cultura digital. In: BARBOSA, Lívia. (org.). Juventudes e gerações no Brasil contemporâneo. Porto Alegre: Sulina, 2012a, p. 61-77.

CASTRO, Gisela G. S. Entretenimento, subjetividade e consumo nas redes digitais: mobilização afetiva como estratégia de negócios. In: BARBOSA, Marialva; MORAIS, Osvando J. (Orgs.). Comunicação em tempo de redes sociais: afetos, emoções, subjetividades. São Paulo: Intercom, 2013, p. 177-198.

CASTRO, Gisela G. S. Lindas para sempre, jovens de coração: imagens do envelhecimento na publicidade natalina. In: CASTRO, Gisela G. S. Os velhos na propaganda: atualizando o debate. São Paulo: Pimenta Cultural, 2018, p. 73-102. Disponível em:

https://www.pimentacultural.com/velhos-na-propaganda . Acesso em: maio 2020.

CETIC.br. TIC Domicílios: Pesquisa sobre o uso das tecnologias da informação e comunicação nos domicílios brasileiros 2017. São Paulo: Comitê Gestor da Internet no Brasil, 2018.

CONANDA (Conselho Nacional dos Direitos da Criança e do Adolescente). Resolução no 163, de 13 de março de 2014. Disponível em:

https://www.direitosdacrianca.gov.br/conanda/resolucoes/163-resolucao-163-de-13-demarco-de-2014/view. Acesso em: maio 2020.

CORRÊA, Luciana. Geração minecraft: uma abordagem cultural sobre o consumo de vídeos por crianças no YouTube Brasil, 5 CONGRESSO INTERNACIONAL EM COMUNICAÇÃO E CONSUMO, 2015, São Paulo. Anais... São Paulo: ESPM, 2015.

CORRÊA, Luciana. Geração youtube: um mapeamento sobre o consumo e a produção de vídeos por crianças. São Paulo: ESPM, 2015a.

CORRÊA, Luciana. Geração youtube: um mapeamento sobre o consumo e a produção de vídeos por crianças. São Paulo: ESPM, 2016.

COSTA, Jurandir Freire. Perspectivas da juventude na sociedade de mercado. In: NOVAES, Regina; VANNUCHI, Paulo. (org.). Juventude e sociedade: trabalho, educação, cultura e participação. São Paulo: Perseu Abramo, p. 75-88, 2003.

DAVIS, Aeron. Promotional culture: the rise and spread of advertising, public relations, marketing and branding. Bristol: Polity, 2013.

DOUGLAS, Mary. ISHERWOOD, Baron. 0 mundo dos bens: para uma antropologia do consumo. Rio de Janeiro: Editora UFRJ, 2013.

LEITE, Paula. Google compra site de vídeo YouTube por US\$ 1,65 bi. Folha de S. Paulo, 10 de outubro de 2006. Disponível em:

https://www1.folha.uol.com.br/fsp/dinheiro/fi1010200602.htm. Acesso em: maio 2020. LEMOS, André. Tecnologia e cibercultura. In: CITELLI, Adilson et al. (org.). Dicionário de Comunicação: escolas, teorias e autores. São Paulo: Contexto, 2014, p. 412-420. 
PEREZ, Clotilde; TRINDADE, Eneus. Consumo midiático: youtubers e suas milhões de visualizações. Como explicar? 26ํㅡㄹ ENONTRO ANUAL DA COMPÓS, 2017, São Paulo. Anais... São Paulo: FLC, 2017.

ROCHA, Everardo. Magia e capitalismo: um estudo antropológico da publicidade. São Paulo: Brasiliense, 2010.

TOMAZ, Renata. 0 que você vai ser antes de crescer? - youtubers, infância e celebridade. Salvador: EDUFBA, 2019.

WERNICK, Andrew. The promotional condition of contemporary culture. In: LEE, Martyn J. (ed.). The consumer society reader. Oxford: Blackwell, 2003, p. 300-318.

\title{
The connected child: young youtubers and the promotion of modes of being a child within the logics of consumption
}

\begin{abstract}
This paper discusses the young youtubers and the modes of being a child promoted by such personalities. Our analysis rests on the YouTube channel Crescendo com Luluca, so as to discuss production of a certain type of subjectivity that we name as the connected child. We consider youtubers as agents that promote certain lifestyles based on the logics of consumption. In our empirical analysis, we highlight three factors that predominate in the production of youtuber Luluca: the use of objects as social markers; the dissemination of aspects related to the daily life of the protagonist; and the use of an informal and relaxed language that can generate closeness between the youtuber and her fan-spectators.
\end{abstract}

\section{Keywords}

Communication and consumption. Connected child. Subjectivity. YouTube. Young youtuber.

\section{Autora correspondente}

Gisela Castro

castro.gisela@gmail.com 


\section{Como citar}

ANDRADE, Marcelo de; CASTRO, Gisela. A criança conectada: os youtubers mirins e a promoção de modos de ser criança nas lógicas do consumo. Intexto, Porto Alegre, n. 52, e-94351, jan./dez. 2021. DOI: http://dx.doi.org/10.19132/1807-8583202152.94351

Recebido em 08/07/2019

Aceito em 14/11/2019

(c) $(1)(9)$ 